\title{
Zonas de manejo em função de propriedades de solo, relevo e produtividade da lavoura cafeeira
}

Bruno Manoel Rezende de Melo ${ }^{1}$

Carlos Maurício Paglis ${ }^{2}$

Marcelo Silva de Oliveira ${ }^{3}$

Marcília Bruna R. Teixeira4

Jennifer S. M. da Silva ${ }^{5}$

Daniele F. F. Lima ${ }^{6}$

\section{Resumo}

O objetivo foi determinar zonas de manejo correlacionando produtividade, altitude, parâmetros de textura e fertilidade de solo em propriedades cafeeiras do sul de Minas Gerais. 0 experimento foi realizado em Inconfidentes (MG), em uma lavoura de café da cultivar Rubi com 0,849 ha-1, no espaçamento 2,2 m x 1,3 m, em dezembro de 2011, em Latossolo Vermelho Amarelo distrófico. O local está situado a 957 metros de altitude com parte da lavoura situada no topo de morro e a outra parte em meia encosta, apresentando declividade máxima entre os pontos de maior e menor altitude de $37 \%$. 0 local para a coleta de solo está situado em cada ponto georreferenciado com um receptor GPS, para a zona 23k no sistema de referências SIRGAS 2000. Posteriormente foram analisados os parâmetros químicos, físicos, altitude e declividade da área. Para verificar a dependência espacial dos fatores em estudo, utilizou-se da geoestatística. Na presença de dependência espacial foram confeccionados os mapas de gradiente. Os resultados demonstram que não foi possível encontrar dependência espacial para o fósforo. Para as variáveis matéria orgânica, potássio, saturação de bases, $\mathrm{pH}$ e declividade foi possível identificar zonas de manejo em função da correlação significativa com a altitude. A produtividade nos dois anos apresentou variabilidade espacial e temporal. Conclui-se, desta forma, que zonas de manejo podem ser identificadas correlacionando altitude com parâmetros de fertilidade. Para a produtividade e textura, nos dois anos de estudos, não foram observadas zonas de manejo.

Palavras-chave: Agricultura de precisão. Geoestatística. Mapas de gradiente.

\footnotetext{
1 Universidade Federal de Lavras, doutorando em Agronomia/Fitotecnia, Lavras, Minas Gerais, Brasil. bruno.melo@ifsuldeminas.edu.br. Departamento de Agricultura/DAG, Av. Doutor Sylvio Menicucci, 1001, Kenndy, Lavras. MG, CEP: 37.200-000.

2 Universidade Federal de Lavras, professor-doutor/pesquisador, Lavras, Minas Gerais, Brasil. paglismau@dag.ufla.br. Departamento de Agricultura/DAG.

3 Universidade Federal de Lavras, professor-doutor/pesquisador, Lavras, Minas Gerais, Brasil. marcelo.oliveira@dex.ufla.br. Departamento de Estatística/DEX.

4 Universidade Federal de Lavras, doutoranda em Estatística e Experimentação Agropecuária, Lavras, Minas Gerais, Brasil. marciliabruna@yahoo.com.br. Departamento de Estatística/DEX.

5 Instituto Federal do Sul de Minas Gerais - Campus Inconfidentes, discente de Engenharia Agronômica, Inconfidentes, Minas Gerais, Brasil.jsmeira@live.com.

6 Instituto Federal do Sul de Minas Gerais - Campus Inconfidentes, discente de Engenharia Agronômica, Inconfidentes, Minas Gerais, Brasil. dani.f.lima@hotmail.com.
} 


\section{Introdução}

Hoje na cafeicultura, o método mais utilizado para verificar a fertilidade dos solos é o proposto por Cantarutti, Alvarez e Ribeiro (1999), sendo que nesta metodologia é considerada a variabilidade do solo existente. Contudo, esse método é renegado pelos produtores e técnicos por não considerar a variabilidade existente, o que eleva a dimensão da heterogeneidade, onerando os custos dos processos, contribuindo para aplicação de insumos com base nas médias (FERRAZ et al., 2011).

$\mathrm{Na}$ determinação destas variabilidades, pesquisadores e alguns agricultores já estão trabaIhando de acordo com zonas de manejo. Essas regiões são representadas pela variação de solos e produtividade (BALASTREIRE, 2002). Essa estratégia é baseada em amostragem em malhas, sendo constituída por operações das quais se obtém material de estudo em uma proporção relativamente pequena, mas que representa de maneira adequada os locais onde foram amostrados, permitindo verificar dependência entre as amostras. Essas amostragens podem ser realizadas pelo método malha celular ou centro da malha (FLOWER; WEISZ; WHITE, 2005).

Partindo da premissa da amostragem de solo, centro da malha, um dos maiores desafios de quem trabalha com Agricultura de Precisão é definir o tamanho adequado dessas áreas, visto que maIhas muito grandes podem não refletir a dependência do atributo em estudo e malhas muito pequenas acabam por onerar de forma demasiada os custos com coleta e análises laboratoriais. Empresas e produtores rurais que atuam em Agricultura de Precisão têm utilizado diferentes tamanhos de malhas e diferentes amostras por malha. Na cafeicultura, as malhas comerciais mais utilizadas apresentam um ponto a cada hectare (FERRAZ et al., 2011).

Visando contornar esse dilema de uma malha de amostragem apropriada, vários autores já discutem a prática de amostragem em zonas de manejo homogêneas ou unidades de gestão diferenciada (MOLIN; CASTRO, 2008).

Zonas de manejo são representadas por subáreas que evidenciam uma combinação homogênea de fatores potencialmente limitantes à produtividade e são de caráter permanente, podendo ser manejadas como unidades individualizadas dentro do talhão (MOLIN; CASTRO, 2008). Esses fatores limitantes estão correlacionados com a produtividade e aspectos técnicos de fertilidade e textura dos solos.

Para Molin e Castro (2008), essa estratégia está baseada em critérios topográficos, cor do solo, atributos físicos do solo, espessura do horizonte $A$, mapas de produtividade de vários ciclos produtivos, condutividade elétrica, histórico da área, vigor, além de critérios conjugados que podem ser utilizados na determinação das zonas de manejo (SHANER; FARAHANI; BUCHLEITER, 2008). $\mathrm{O}$ uso dessas delimitações por meio de zonas de manejo pode ser uma alternativa em agricultura de precisão, pois permite otimizar os trabalhos visando eficiência produtiva da área com redução de custos, associando esses fatores à facilidade de manejo (VALENTE, 2010).

Anchieta (2012) afirma que a Agricultura de Precisão não pode limitar-se apenas a modelos de malhas universais para o levantamento das características do solo haja vista que cada lavoura adapta-se às condições da paisagem, histórico da área, tipo de solo etc, exigindo novas ferramentas para determinar zonas distintas de manejo.

O objetivo deste estudo foi determinar zonas de manejo, associando produtividade, altitude, parâmetros de textura e fertilidade de solo em propriedades cafeeiras do sul de Minas Gerais. 


\section{Material e métodos}

O experimento foi realizado na cidade de Inconfidentes (MG), na Fazenda-Escola do IFSUDEMINAS-Campus Inconfidentes, em uma lavoura de café da cultivar Rubi com 0,849 ha-1, implantada no espaçamento 2,2 m x 1,3 m, em dezembro de 2011. A coordenada geográfica da área é $22^{\circ} 18^{\prime} 42^{\prime \prime}$ latitude sul e 46²0'12" longitude oeste. O clima do local é considerado tropical de altitude, com inverno seco, verão quente e chuvoso, classificado como Cwa de acordo com Köppen. 0 solo da área é categorizado como Latossolo Vermelho Amarelo distrófico. O local está situado a 957 metros de altitude com parte da lavoura situada no topo de morro e a outra parte em meia encosta, apresentando declividade máxima entre os pontos de maior e menor altitude de 37 \%. A Figura 1 apresenta o mapa sobre a localização da área e dos pontos amostrados.

O local para a coleta de solo está situado em cada ponto georreferenciado, com um receptor GPS, modelo Etrex 20 Garmim, nas coordenadas cartesianas bidimensionais UTM (Universal Transversa de Mercator) para a zona 23k no sistema de referências SIRGAS 2000. Os locais com os respectivos pontos foram demarcados com a utilização de folhas de E.V.A.

Figura 1-Localização da Lavoura Fazenda-Escola com a respectiva malha amostral.

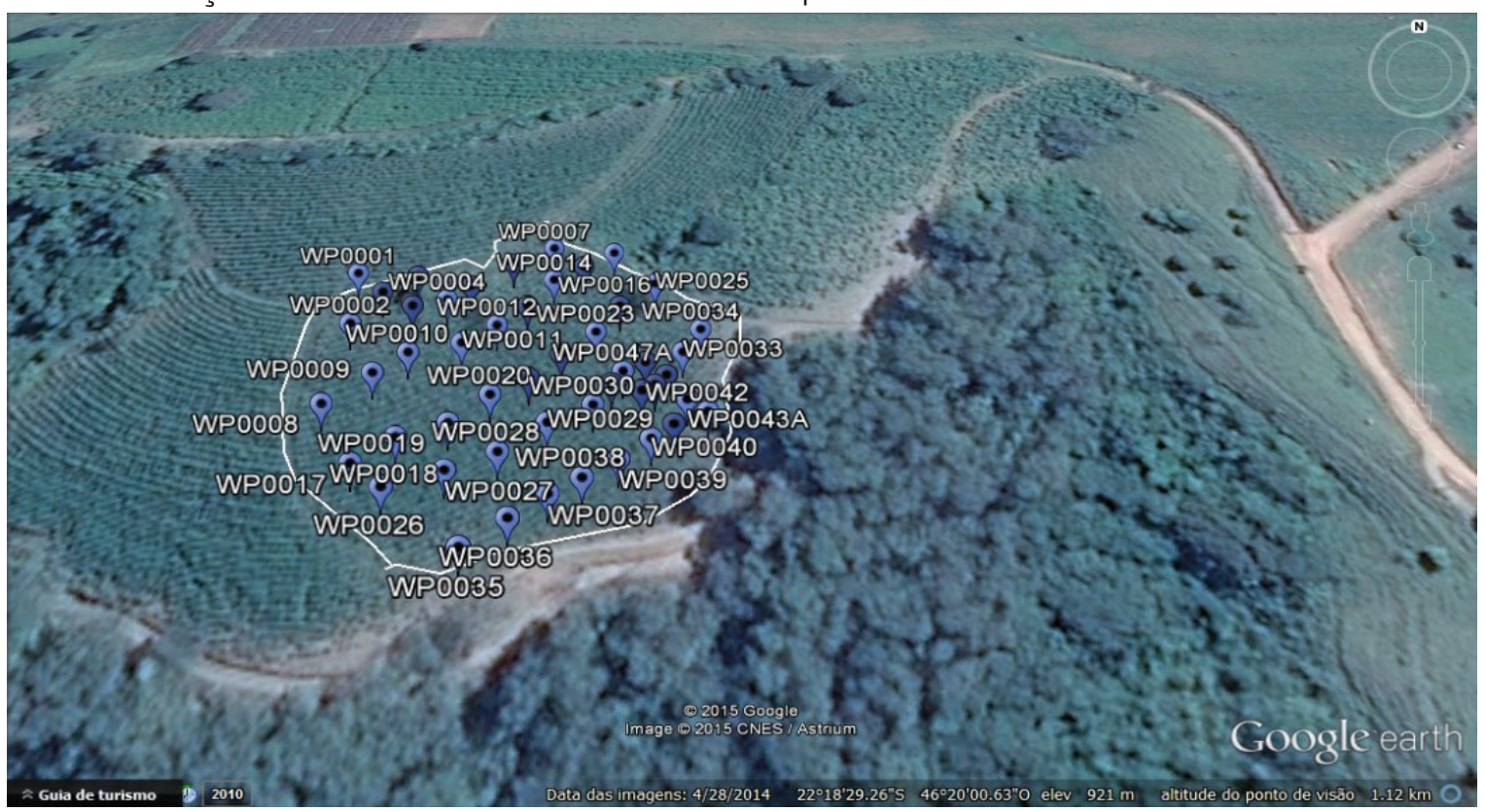

Fonte: Google Earth - modificada pelos autores (2014)

Para perfazer uma amostra composta foram necessárias cinco subamostras, retirada uma da coordenada central e as demais subamostras localizadas nas quatro plantas no entorno do ponto central, orientadas pelos pontos cardeais.

As coletas de solos foram realizadas em julho de 2014 , retiradas na projeção dos ramos plagiotrópicos, na profundidade de 0 a $20 \mathrm{~cm}$, com o uso de um trado tipo holandês, sendo amostradas em 42 pontos de coleta, com malha amostral regular espaçada a 10,4 metros na linha e na entrelinha a cada 17,6 metros.

O volume de solo dessas subamostras foi homogeneizado para formar uma amostra composta, sendo retirados do montante 300 gramas de solo, que posteriormente foram enviados para o Laboratório de Solo do IFSULDEMINAS- Campus Inconfidentes.

As amostras para análise física são oriundas da análise química e foram enviadas ao Laboratório de Física de Solo do IFSULDEMINAS- Campus Inconfidentes. 
Na determinação da produtividade por planta foi considerada a mesma malha amostral utilizada para os parâmetros de solo.

A avaliação da produtividade foi obtida pela derriça manual de sete plantas. A primeira planta estava situada no ponto georreferenciado e as demais foram divididas em três plantas para cada direção da linha da cultura.

A colheita foi feita em junho de 2014 e 2015. Esse procedimento ocorreu pela derriça manual dos frutos em pano. 0 volume colhido após a abanação foi mensurado em um recipiente graduado, obtendo-se o valor médio de produtividade para cada planta na coordenada demarcada.

Os resultados das análises químicas, textura de solo e produtividade foram submetidos à análise geoestatística e estatística descritiva utilizando o software estatístico $\mathrm{R}$ com o pacote geo $\mathrm{R}$ (RIBEIRO JUNIOR; DIGGLE, 2001). Foi realizado estudo para verificar a existência de tendência e na sua presença foram removidos na direção ao eixo $X$ e $Y$.

Na existência de dependência espacial, os dados foram analisados por meio dos semivariogramas, sendo o método dos mínimos quadrados ordinários utilizado para definir o melhor ajuste do semivariograma, considerando os modelos gaussiano, linear, esférico e exponencial. Na determinação do melhor modelo, utilizou-se da autovalidação, na qual foi observada a melhor inclinação da reta a $45^{\circ}$. Na presença de dependência espacial, os dados foram interpolados por meio da krigagem ordinária, pela qual foram feitos os mapas dos parâmetros fósforo, potássio, pH, saturação de bases, matéria orgânica, argila, altitude, declividade e produtividade para os anos de 2014 e 2015 . Também foi utilizado o coeficiente de correlação de Pearson a $5 \%$ de probabilidade para verificar o grau de associação entre os fatores em estudos.

\section{Resultados e discussão}

Com exceção do fósforo, todos os parâmetros em análise apresentaram dependência espacial. Ferraz et al. (2012) verificaram dependência espacial para o atributo fósforo, potássio e matéria orgânica, corroborando parte dos resultados encontrados.

O mapa de altitude, Figura 2B, na porção do mapa com a cor mais avermelhada evidencia uma área da lavoura que se encontra em uma região com maior altitude associada a uma região com menor declividade como demonstrado na Figura 2A.

A declividade do relevo influencia sobremaneira alguns parâmetros de fertilidade. Por meio dos mapas $(A)$ potássio, $(B)$ matéria orgânica, $(C)$ potencial hidrogeniônico e $(D)$ saturação por bases, Figura 3, observa-se que na porção mais plana do relevo, Figura $2(A)$, e com maior altitude, Mapa $B$, constatam-se maiores teores do potássio, matéria orgânica, pH e saturação por bases. Contudo, à medida que há decréscimo de altitude, há redução dos valores dos parâmetros de fertilidade em estudo.

O comportamento dessas variáveis, Figura 3, demonstra a grande influência do relevo no comportamento de alguns parâmetros químicos do solo que, por sua vez, apresenta relação com as características de lixiviação e arraste de partículas na direção da região de menor altitude, mapa $B$ Figura 2. Para a análise da altitude, característica intrínseca do relevo, verifica-se que essa abordagem deve ser considerada para definição de zonas de manejo, pois, de acordo com o coeficiente de correlação, identifica-se correlação significativa de 0,52 para o potássio, 0,54 para a saturação de bases e de 0,49 para o pH, Tabela 1 . Esse resultado provavelmente ocorre devido à redução dos processos erosivos, causada pelo aumento da altitude, Figura 2 - Mapa B, com abatimento da declividade, Figura 2 Mapa B, ocasionando redução dos processos erosivos. 
De acordo com a Figura 3-Mapa B, para a variável matéria orgânica, verifica-se que as regiões com maior teor desse atributo apresentam também maiores teores de saturação de bases e potencial hidrogeniônico, Mapas C e D.

Figura 2: Mapa de gradientes para a porcentagem de declividade (A) e altitude (B).
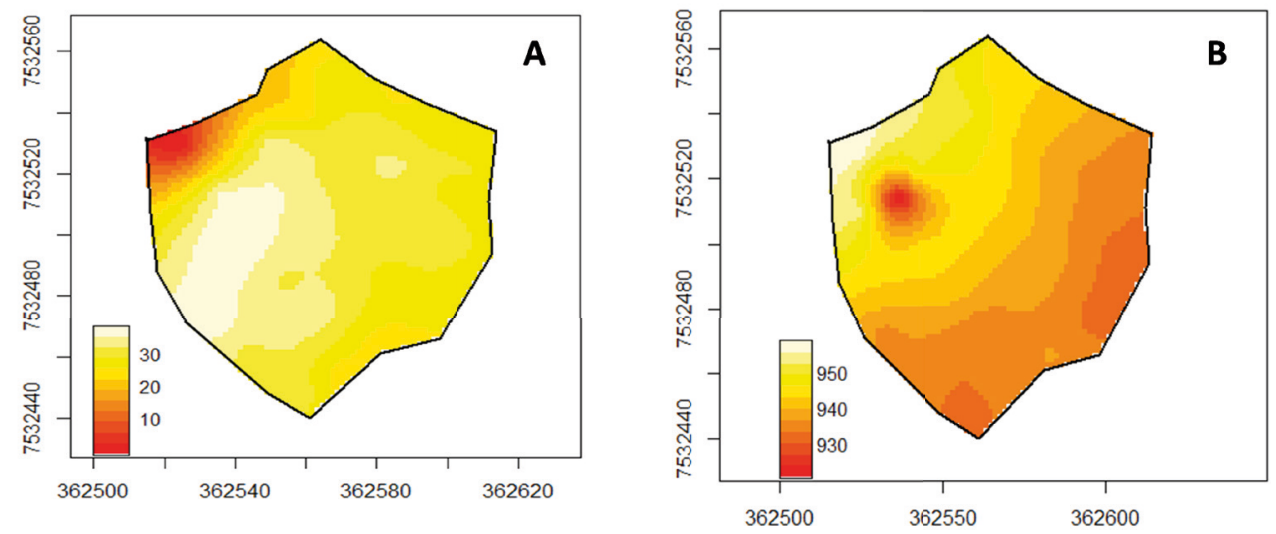

Fonte: Elaborada pelos autores.

Figura 3: Mapa de gradiente para potássio $(A)$, matéria orgânica $(B)$, potencial hidrogeniônico $(C)$, saturação por bases, (D).
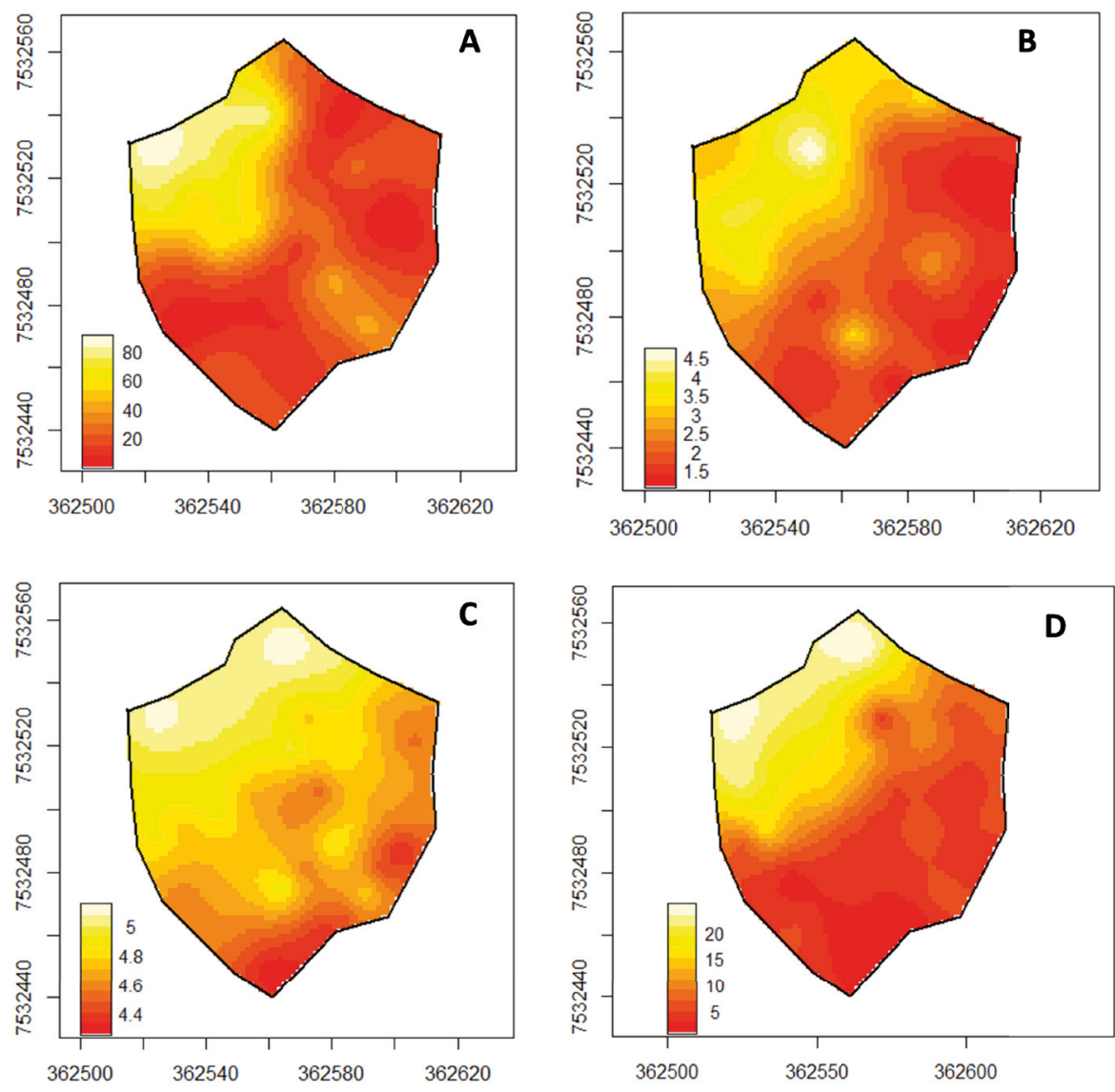

Fonte: Elaborada pelos autores.

No estudo da correlação entre altitude e matéria orgânica, verificou-se que esta foi significativa, Tabela 2, definindo, portanto, zonas homogêneas passíveis de serem trabalhadas. De acordo com Alves et al. (2013), as zonas de manejo que melhor definiram os atributos químicos foram os mapas de matéria orgânica e altitude, corroborando os resultados encontrados. 
Segundo Khosla et al. (2010), a base na definição de zonas de manejo devem ser identificadas por meio de propriedades de cultivo e de solo que caracterizam de forma mais precisa as variações agronomicamente significativas e que são passíveis de ser trabalhadas.

Essas zonas devem ser resultantes de avaliações simples, estáveis e de baixo investimento, que permitam o manejo da taxa variável entre zonas com características semelhantes, sendo que o relevo apresenta todas essas características (KHOSLA et al., 2010).

Tabela 1. Análise de correlação entre altitude e os parâmetros potássio, argila, matéria orgânica, potencial hidrogeniônico, saturação por bases, produtividade L/pl 2014 e produtividade L/pl 2015.

\begin{tabular}{ccccccc}
\hline $\begin{array}{c}\text { Altitude/ } \\
\text { potássio }\end{array}$ & $\begin{array}{c}\text { Altitude/ } \\
\text { argila }\end{array}$ & $\begin{array}{c}\text { Altitude/ } \\
\text { matéria } \\
\text { orgânica }\end{array}$ & Altitude/ pH & $\begin{array}{c}\text { Altitude/ } \\
\text { saturação de } \\
\text { bases }\end{array}$ & $\begin{array}{c}\text { Altitude/ } \\
\text { produtividade } \\
2014\end{array}$ & $\begin{array}{c}\text { Altitude/ } \\
\text { produtividade } \\
2015\end{array}$ \\
\hline $0,52^{*}$ & $0,21^{* *}$ & $0,48^{*}$ & $0,49^{*}$ & $0,54^{*}$ & $0,23^{* *}$ & $0,35^{*}$ \\
\hline
\end{tabular}

*significativo a $5 \%$ probabilidade

** não significativo a $5 \%$ probabilidade

Fonte: Elaborada pelos autores

Por meio das variações expressas nos mapas de gradiente das Figuras 2 e 3, observa-se grande variabilidade, tendo em vista a grande amplitude dos parâmetros em estudo, contudo, Santi et al. (2009) destacam que caso toda variabilidade seja considerada na aplicação de insumos à taxa variável, essa acarretaria custos que não seriam pagos pelos rendimentos da cultura, pois exigiria investimentos em equipamentos de alto custo não compensando os resultados dos trabalhos realizados. McBratney (2008) salienta que em pequenas zonas de variabilidade, dadas as limitações técnicas e econômicas, não se justifica o tratamento a toda variabilidade verificada.

$\mathrm{Na}$ definição de zonas de manejo por meio da análise do relevo, associada ao percentual de argila, não observou-se a zona específica de manejo, haja vista a distribuição irregular do percentual desta variável ao longo da área, Figura 4 Mapa A. Na análise de correlação entre o teor de argila e altitude, não se verificou correlação significativa, Tabela 1. Mesmo não havendo correlação da argila com o percentual de declividade, a argila é muito estudada em trabalhos com definição de zonas de manejo, tendo em vista suas propriedades.

Conforme Machado et al. (2006), processos relacionados para descrever o comportamento da argila nas áreas agrícolas produzem informação imprescindível, visto que o reconhecimento da distribuição desse atributo possibilita definir unidades de zonas de manejo, refinando os processos de amostragem.

Outra característica que reforça o estudo da argila como um dos principais componentes em determinar unidade de manejo diferenciada é a capacidade dessa variável na determinação da água disponível para as plantas que, por sua vez, influencia a produtividade (STAFFORD et al. 1996).

Nunes et al. (2010) destacaram que os atributos físicos do solo apresentam variação e têm potencial para influenciar de forma decisiva o manejo a ser adotado nas áreas cultivadas, além de ter importante papel na expressão produtiva da cultura. Durigon et al. (2009), demonstrando a importância da argila em relação à produtividade, identificaram correlação positiva entre esses parâmetros.

O estudo associado da argila e das características da paisagem no contexto da AP já tem sido utilizado como critério para delimitar zonas de manejo, sendo essa uma das propostas para otimizar o gerenciamento das atividades na definição de zonas de manejo. 0 uso dessa variável na definição de áreas mais uniformes possibilita reduzir custos com amostragem em malhas (MOLIN, 2002), uma vez que o processo de amostragem passa a ser o método da malha celular.

Os parâmetros de correlação significativa da altitude com o potássio, com a matéria orgânica, potencial hidrogeniônico e saturação de bases, Tabela 1, indicou baixa correlação, contudo Dalchia- 
von et al. (2013) afirmam que o grande número de dados utilizados pode provocar baixa magnitude do coeficiente de correlação.

Figura 4: Mapa de gradiente para Argila (A), produtividadeL/pl 2014, (B) produtividadeL/pl 2015, (C).
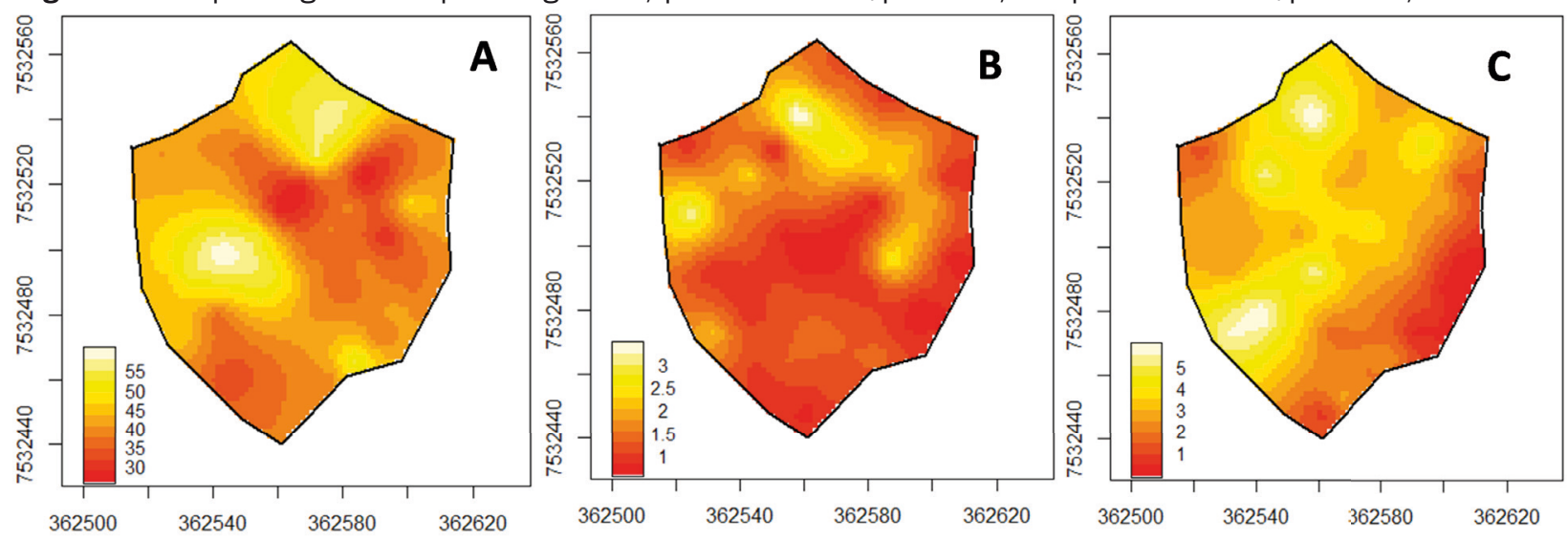

Fonte: Elaborada pelos autores.

Para a correlação de produtividade com o pH e saturação de bases também se observou baixo coeficiente de correlação, Tabela 2. Da mesma forma, Silva et al. (2007) identificaram baixo correlação entre produtividade e atributos químicos.

Molin (2008) destaca que é comum encontrar baixa correlação entre produtividade e fatores isolados. Esse resultado pode ser explicado devido ao grande número de fatores envolvidos na produção das lavouras.

Os mapas de produtividades de 2014 e 2015, Figura 3 - Mapas B e C, não permitiram verificar zonas de manejo. Nesses dois anos de estudos, os extremos pontuais de produtividade demonstraram grande variabilidade de produção tanto espacialmente quanto temporalmente, o que pode ser justificado pela variabilidade espacial de outros fatores envolvidos na produção. Essa variabilidade pode estar relacionada às variáveis que limitam a produtividade em zonas de baixa produtividade (MOLIN, 2002), associadas aos fatores intrínsecos e extrínsecos do solo.

É importante salientar que na Figura $3 \mathrm{~B}$, a região com menor produção demonstra uma área do mapa com menor altitude e maior declive. Observação semelhante foi verificada para os atributos potássio, matéria orgânica e saturação por bases onde foi verificado menor teor desses atributos, no qual podem ter contribuído para menor produção.

Souza et al. (2004) afirmaram que fatores como declividade e posição topográfica influenciam a produtividade das culturas de maneira indireta, por induzir o carreamento dos atributos químicos e físicos do solo. Silva et al. (2007) corroboram afirmando que em regiões de maior declive a produtividade é menor.

Para correlação de produtividade de 2014 com os demais parâmetros de solo, o maior e mais significativo índice foi encontrado para o pH e saturação de bases, indicando grande influência na concentração de bases em contribuir para o aumento da produtividade (Tabela 2).

Tabela 2. Análise de correlação entre produtividade de 2014 e os parâmetros potássio, argila, matéria orgânica, potencial hidrogeniônico e saturação por bases.

\begin{tabular}{ccccc}
\hline $\begin{array}{c}\text { Produtividade/ } \\
\text { potássio }\end{array}$ & $\begin{array}{c}\text { Produtividade/ } \\
\text { argila }\end{array}$ & $\begin{array}{c}\text { Produtividade/ } \\
\text { matéria orgânica }\end{array}$ & Produtividade/ $\mathrm{pH}$ & $\begin{array}{c}\text { Produtividade/ } \\
\text { saturação de bases }\end{array}$ \\
\hline $0,21^{* *}$ & $0,06^{* *}$ & $0,24^{* *}$ & $0,53^{*}$ & $0,47^{*}$ \\
\hline
\end{tabular}

*significativo a $5 \%$ probabilidade

** não significativo a $5 \%$ probabilidade

Fonte: Elaborada pelos autores. 
Esses resultados já eram esperados haja vista a contribuição que um pH próximo do adequado exerce na produtividade. No estudo da altitude verificou-se correlação significativa entre este parâmetro e a produtividade no ano de 2015. Contudo, para as demais correlações de produtividade de 2014 , verificaram-se correlações não significativas para o potássio, argila e matéria orgânica, Tabelas 1 e 2.

Molin, Amaral e Colaço (2001) destacam que o mapa de produtividade é a informação mais importante para visualizar a variabilidade das lavouras. De acordo com Balastreire (2002), o resultado da colheita é tido como a expressão biológica dos fatores envolvidos no processo produtivo, sendo uma das fases que apresenta maior facilidade na confecção de mapas de produtividade. Molin (2002) afirma que os mapas de produtividade são ferramentas importantes, por permitirem o estabelecimento de zonas de manejo, indicando possíveis áreas com características semelhantes. Segundo o mesmo autor a definição de zonas de manejo com base na produtividade é uma alternativa viável, tendo em vista que os maiores gastos serão na contratação de mão de obra especializada e/ou a adequação de automotrizes com monitor de produtividade. Por conseguinte, quando definidas essas zonas, as amostragens em malhas são eliminadas, direcionando as coletas de solo para cada zona de manejo em sistema de malha celular (MOLIN, 2002).

\section{Conclusões}

Conclui-se que zonas de manejo podem ser realizadas correlacionando altitude com parâmetros de fertilidade. Para a produtividade nos dois anos de estudos e para a textura não foram observadas zonas de manejo.

\section{Agradecimentos}

Ao IFSULDEMINAS - Campus Inconfidentes pela concessão de bolsa-pesquisa e de incentivo à qualificação.

\section{Management areas due to soil properties, topography and productivity of coffee plantations}

The aim was to determine management zones correlating productivity, altitude, texture parameters and soil fertility in coffee states in southern Minas Gerais. The experiment was conducted in Inconfidentes (MG), in a 0.849 ha $^{-1}$ Ruby cultivate coffee plantation, allocated in $2.2 \mathrm{~m} \times 1.3 \mathrm{~m}$ spacing, in December 2011, in Oxisol dystrophic. The place is located 957 meters above sea level with some of the crop located on top of the hill and the other party in half hillside, with maximum slope between the points of highest and lowest elevation of $37 \%$. The site for soil collection is located at each georeferenced point with a GPS receiver, for $23 \mathrm{k}$ zone in the reference system SIRGAS 2000. The chemical, physical, altitude and slope of the area were later analyzed. To check the spatial dependence of the factors in studies, geostatistics were used. In the presence of spatial dependence, the gradient maps were made. The results demonstrate that it was not possible to find spatial dependence for the phosphor. For the variables organic matter, potassium, bases saturation, and $\mathrm{pH}$ gradient, the management areas were possible to identify due to the significant correlation with altitude. Productivity in the two years presented spatial and temporal variability. Therefore, it was concluded that management areas can be identified by correlating altitude fertility parameters. For productivity and texture in the two years the study was conducted, management zones were not observed. Keywords: Precision agriculture. Geostatistics. Gradient map. 


\section{Referências}

ALVES, S. M.; ALCANTARA, G. R. de; REIS, E. F. de; QUEIROZ, D. M. de; VALENTE, D. S. M. Definição de zonas de manejo a partir de mapas de condutividade elétrica e matéria orgânica. Bioscience Journal, Uberlândia, v. 29, n. 1, p. 104-114, jan./feb. 2013. Disponível em: <http://www.seer.ufu. br/index.php/biosciencejournal/article/view/13687> . Acesso em: 23 nov. 2014.

ANCHIETA, L. Amostragem de solo em agricultura de precisão: particularidades e recomendações. 2012. 108 f. Dissertação (Mestrado Ciências: Solos e Nutrição de Plantas) - Escola Superior de Agricultura "Luiz de Queiroz", Piracicaba, 2012. Disponível em: < http://www.teses.usp.br/teses/disponiveis/11/11140/tde-16082012-105301/pt-br.php>. Acesso em: 21 nov. 2014.

BALASTREIRE, L. A (Coord. Editorial). Avanços na Agricultura de Precisão no Brasil no Período de 1999-2001. (SIMPÓSIO DE AGRICULTURA DE PRECISÃO, 3, Piracicaba, 2001) Piracicaba, 2002. 347p, CD-Rom.

CANTARUTTI, B. R.; VENEGAZ, V. H.; RIBEIRO, A. C. Amostragem de solo. In: RIBEIRO, A. C.; GUIMARÃES, P. T. G.; VENEGAZ, V. H. A. Recomendações para o uso de corretivos e fertilizantes em Minas Gerais: 5a aproximação. Viçosa: UVF, 1999. cap. 3. p. 21-27.

DALCHIAVON, F. C.; CARVAlHO, M. P. de; ANDRADE, F. G.; MONTARANI, R.; ANDREOTI, M. Produtividade da cana-de-açúcar e definição de zonas específicas de manejo do solo. Semina: Ciências Agrárias, Londrina, v. 34, n. 5, p. 2077-2088, set./out. 2013. Disponível em: <www.uel.br/revistas/uel/index.php/semagrarias/article/download/11043>. Acesso em: 25 nov. 2014.

DURIGON, R.; SCHLOSSER, J. F.; RUSSINI, A.; DORNELLES, M. E. C.; PINHEIRO, E. D. Correlações entre atributos da cultura e da produtividade e da produtividade de arroz irrigado determinado com técnicas de manejo localizado. Ciência Rural, Santa Maria, v. 39 n. 9, p. 2629-2633, dez. 2009. Disponível em: <http://www.scielo.br/pdf/cr/v39n9/a360cr867.pdf>. Acesso em: 21 nov. 2014.

FERRAZ, G. A. S.; SILVA, F. M. da; CARVALHO, F. M.; COSTA, A. N. da. Viabilidade econômica do sistema de adubação diferenciado comparado ao sistema de adubação convencional em lavoura cafeeira: um estudo de caso. Engenharia Agrícola, Jaboticabal, v. 31, n. 5, p. 906-915, set./out. 2011. Disponível em: <http://www.scielo.br/scielo.php?script=sci_arttext\&pid=S0100-69162011000500008>. Acesso em: 25 nov. 2014.

FERRAZ, G. A. S.; SILVA, F. M. da; COSTA, P. A. N. da; SILVA, A. C.; CARVALHO, F. M. Agricultura de precisão no estudo de atributos químicos do solo e da produtividade de lavoura cafeeira. Coffee Science, v. 7, p. 59-67, 2012. Disponível em: <http://www.coffeescience.ufla.br/index.php/Coffeescience/article/view/204>. Acesso em: 14 jul. 2014.

FLOWERS, M.; WEISZ, R.; WHITE, J. G. Yield-based management zones and grid sampling, strategies: describing soil test and nutrient variability. Agronomy Journal, Madison, v. 97, p. 968-982, May-June, 2005. Disponível em: <https://naldc.nal.usda.gov/download/3696/PDF>. Acesso em: 25 nov. 2014.

KHOSLA, R.; WESTFALL, R. M.; REICH, J. S.; MAHAL, J. S. Spatial variation and site-specific management zones. In: OLIVER, M. A (Ed.). Geostatistical Applications for Precision Agriculture. 
Springer Netherlands, 2010. cap. 8, p. 195-219. Disponível em:< http://link.springer.com/chapter/10.1007/978-90-481-9133-8_8\#page-1>. Acesso em: 25 nov. 2014.

MACHADO, P. L. O. A.; BERNARDI, A. C. C.; VALENCIA, L. I. O.; MOLIN, J. P.; GIMENEZ, L. M.; SILVA, C. A.; ANDRADE, A. G. de; MADARI, B. E.; MEIRELLES, M. S. P. Mapeamento da condutividade elétrica e relação com a argila de Latossolo sob plantio direto. Pesquisa Agropecuária Brasileira, v. 41, n. 6, p. 1023-1031, jun. 2006. Disponível em: <http://www.scielo.br/pdf/\%0D/pab/ v41n6/30870.pdf> Acesso em: 12 ago. 2014.

MCBRATNEY, A.; WHELAN, B.; ANCEV, T.; BOUMA, T. Future directions of precision agriculture. Precision Agriculture, v. 6, n. 1, p. 7-23, Feb. 2005.

MOLIN, J. P. ; AMARAL, L. R. do; COLAÇO, A. F. Agricultura de precisão: o gerenciamento da variabilidade. Piracicaba: O Autor, 2001. p. 25-35.

MOLIN, J. P. Definição de unidades de manejo a partir de mapas de produtividade. Engenharia Agrícola, Jaboticabal, v. 22, n. 1, p. 83-92, 2002. Disponível em: <https://www.researchgate.net/profile/Jose_Molin/publication/268011698_DEFINICAO_DE_UNIDADES_DE_MANEJO_A_PARTIR_DE_ MAPAS_DE_PRODUTIVIDADE/links/5487334c0cf2ef34478ec44f.pdf > Acesso em: 10 jun. 2014.

MOLIN, J. P.; CASTRO, C. N. Establishing management zones using soil electrical conductivity and other soil properties by the fuzzy clustering technique. Scientia Agricola, Piracicaba, v. 65, p. 567-573, nov./dez. - 2008. Disponível em: <www.scielo.br/scielo.php?pi$d=$ S0103-90162008000600001\&script=sci_arttext $>$. Acesso em: 25 nov. 2014.

NUNES, L. A. P. L.; DIAS, L. E.; JUCKSH, I.; BARROS, N. F. de. Atributos físicos do solo em área de monocultivo de cafeeiro na Zona da Mata de Minas Gerais. Bioscience Journal, Uberlândia, v. 26, n. 1, p. 71-78, jan./fev. 2010. Disponível em: <http://www.seer.ufu.br/index.php/biosciencejournal/ article/view/7040>. Acesso em: 12 maio 2014.

RIBEIRO JUNIOR, P. J.; DIGGLE, P. J. GeoR a package for geoestatitical anlysis. R-News, New York, v. 1/2, p. 14-18, June, 2001. Disponível em: < https://www.researchgate.net/profile/Paulo_Ribeiro_Jr/publication/224840049_GeoR_A_Package_for_Geostatistical_Analysis/links/553e94170cf20184050f8914.pdf>. Acesso em: 12 abr. 2014.

SANTI, A. L.; AMADO, T. J. C.; FLORA, L. P. D.; SMANIOTTO, R. F. F. É chegada a hora da integração do conhecimento. Revista Plantio Direto, Passo Fundo, v. 129, n. 1, p. 24-30, 2009. Disponível em: <http://w3.ufsm.br/projetoaquarius/pdfs/artigos/_a_revistaplantiodiretochegadaahora.pdf >. Acesso em: 12 abr. 2014.

SILVA, F. M.; SOUZA, Z. M. de; FIGUEIREDO, A. P. de; MARQUES JUNIOR, J.; MACHADO, R. V. Variabilidade espacial de atributos químicos e de produtividade na cultura do café. Ciencia Rural, v. 37, n. 2, p. 401-407, 2007. Disponível em: <http://www.scielo.br/scielo.php?script=sci_arttext\&pid=S0103-84782007000200016\&lng=pt\&nrm=iso\&tlng=pt>. Acesso em: 12 abr. 2014.

SHANER, D. L.; FARAHANI, H. J.; BUCHLEITER, G. W. Predicting and Mapping Herbicide: Soil Partition Coefficients for EPTC, Metribuzin, and Metolachlor on Three Colorado Fields. Weed Science, 
v. 56, p. 133-139, Jan./Feb. 2008. Disponível em: <https://www.jstor.org/stable/25148489?se$\mathrm{q}=1$ \#page_scan_tab_contents $>$. Acesso em: 21 jun. 2016.

SOUZA, Z. M.; MARQUES JUNIOR, J.; PEREIRA, G. T.; MOREIRA, L. F. Variabilidade espacial do $\mathrm{pH}, \mathrm{Ca}, \mathrm{Mg}$ e V\% do solo em diferentes formas do relevo sob cultivo de cana-de-açúcar. Ciência Rural, Santa Maria, v. 34, n. 6, p. 1763-1771, nov./dez. 2004. Disponível em: <http://www.scielo.br/ scielo.php?script=sci_arttext\&pid=S0103-84782004000600015\&lng $=$ pt\&nrm $=i s o \& t \operatorname{lng}=p t>$. Acesso em: 11 jun. 2014.

STAFFORD, J. V.; AMBLER, B.; LARK, R. M.; CATT, J. Mapping and interpreting yield variation in cereal crops. Computers and Electronics in Agriculture, New York, v. 14, p. 101-119, Feb. 1996.

VALENTE, D. S. M. Desenvolvimento de um sistema de apoio à decisão para definir zonas de manejo em cafeicultura de precisão. 2010. 122 f. Tese (Doutorado em Engenharia Agrícola) - Universidade Federal de Viçosa, Viçosa, 2010. Disponível em: <http://www.sbicafe.ufv.br/bitstream/handle/123456789/5553/Tese_Domingos\%20Sarvio\%20Magalhaes\%20Valente. pdf?sequence $=1 \& \mathrm{i}-$ sAllowed=y> Acesso em: 21 junho 2016.

\section{Histórico editorial:}

Submetido em: 19/11/2015

Aceito em: 01/06/2016

Como citar:

$\underline{A B N T}$

MELO, B. M. R de; PAGLIS, C. M.; OLIVEIRA, M. S. de; TEIXEIRA, M. B. R.; SILVA, J. S. M. da; LIMA, D. F. F. Zonas de manejo em função de propriedades de solo, relevo e produtividade da lavoura cafeeira. Revista Agrogeoambiental, Pouso Alegre, v. 9, n. 2, p. 49-59, abr.jun. 2017. Doi: http://dx.doi.org/10.18406/2316-1817v9n22017924

APA

MELO, B. M. R de, PAGLIS, C. M., OLIVEIRA, M. S. de, TEIXEIRA, M. B. R., SILVA, J. S. M. da \& LIMA, D. F. F. (2017). Zonas de manejo em função de propriedades de solo, relevo e produtividade da lavoura cafeeira. Revista Agrogeoambiental, Pouso Alegre, 9 (2), 49-59. Doi: http://dx.doi.org/10.18406/2316-1817v9n22017924

$\underline{\mathrm{ISO}}$

MELO, B. M. R de; PAGLIS, C. M.; OLIVEIRA, M. S. de; TEIXEIRA, M. B. R.; SILVA, J. S. M. da e LIMA, D. F. F. Zonas de manejo em função de propriedades de solo, relevo e produtividade da lavoura cafeeira. Revista Agrogeoambiental, 2017, vol. 9, n. 2, pp. 49-59. Eissn 2316-1817. Doi: http://dx.doi.org/10.18406/2316-1817v9n22017924

\section{VANCOUVER}

Melo BMR, Paglis CM, Oliveira MS, Teixeira MBR, Silva JSM, Lima DFF. Zonas de manejo em função de propriedades de solo, relevo e produtividade da lavoura cafeeira. Rev agrogeoambiental. 2017 abr/jun; 9(2): 49-59. Doi: http://dx.doi.org/10.18406/2316-1817v9n22017924 